\title{
A new model of Type 2 (non-insulin-dependent) diabetes mellitus in spontaneously hypertensive rats: diabetes induced by neonatal streptozotocin treatment
}

\author{
M. Iwase, M. Kikuchi, K. Nunoi, M. Wakisaka, Y. Maki, S. Sadoshima and M. Fujishima \\ Second Department of Internal Medicine, Kyushu University, Fukuoka, Japan
}

Summary. This study was designed to develop an animal model of Type 2 (non-insulin-dependent) diabetes with persistent hypertension. Male spontaneously hypertensive rats were treated with $25.0,37.5,50.0,62.5$ or $75.0 \mathrm{mg} / \mathrm{kg}$ of streptozotocin given intraperitoneally at 2 days of age and maintained for 12 weeks. In the rats which received $50.0 \mathrm{mg} / \mathrm{kg}$ or more streptozotocin, overt hyperglycaemia gradually and consistently developed following incomplete recovery from an initial hyperglycaemia. Compared to vehicle-treated controls, body weight gain in these animals did not differ for the first 8 weeks; thereafter, it was slightly but significantly $(p<0.05)$ reduced. The animals treated with 25.0 or $37.5 \mathrm{mg} / \mathrm{kg}$ streptozotocin developed mild to moderate hyperglycaemia, but their body weight gain was similar to controls. The relationships between streptozotocin dose and metabolic responses (plasma glucose, glycosylated haemoglobin, urinary glucose, food intake, etc.) were clearly demonstrated. Systolic blood pressure rose with progressing age in both controls and streptozotocintreated rats, irrespective of dosage or metabolic response. This new rat model of Type 2 diabetes associated with persistent hypertension may be useful in studying these combined effects on small and large vessels.

Key words: Hypertension, streptozotocin, animal model, spontaneously hypertensive rats, Type 2 (non-insulin-dependent) diabetes mellitus.
Type 2 (non-insulin-dependent) diabetes mellitus in humans is frequently accompanied with hypertension [1]. This association is known to be related to the obesity commonly seen in Type 2 diabetes, and is also considered an important risk factor for cardio- and cerebrovascular diseases. In addition, diabetic nephropathy and retinopathy are accelerated in the presence of hypertension, although the exact effects of these combinations on small and large vessels are not fully understood [1]. There have been a few animal models of diabetes and hypertension [2-4], but a model of Type 2 diabetes associated with hypertension has not been established. Recently, Portha et al. [5] and Bonner-Weir et al. [6] have developed a new rat model of Type 2 diabetes which is experimentally induced by neonatal streptozotocin (STZ) treatment. Adopting this model, we designed the present study to develop a Type 2 diabetes-hypertension model using spontaneously hypertensive rats in which STZ was given 2 days after birth. The relationships between STZ dosage and the metabolic and blood pressure changes were examined at various intervals after STZ given for 12 weeks.

\section{Materials and methods}

Spontaneously hypertensive rats (SHR) were bred in specific pathogen free condition in Kyushu University Animal Centre, where temperature $\left(24^{\circ} \mathrm{C}\right.$ ), humidity (60\%), and lighting (on $08.00-20.00$ hours) were well controlled. They had free access to tap water and standard chow diet. Two-day-old male SHR neonates were intraperitoneally injected through a 27 -gauge microsyringe with STZ (Upjohn Co., Kalamazoo, Mich, USA) dissolved in $0.1 \mathrm{~mol} / 1$ citrate buffer, $\mathrm{pH} 4.5$. Doses of STZ given were varied as $25.0,37.5,50.0,62.5$ and $75.0 \mathrm{mg}$ / $\mathrm{kg}$, but the injection volume was the same ( $4 \mu \mathrm{l} / \mathrm{g}$ body weight). Control rats received an equivalent amount $(4 \mu \mathrm{l} / \mathrm{g})$ of citrate buffer without STZ (vehicle-treated). To prevent leaking of the solution, the injection site was glued with a strong adhesive agent, Aron Alpha A (Sankyo, Tokyo, Japan). The neonates were left with their own mother, and were weaned at 4 weeks of age. Litter size ranged from 3 to 8 $(6.2 \pm 0.4$, mean \pm SEM).

Body weight was measured weekly until 12 weeks of age. Blood samples were obtained by cardiac puncture with a 28 gauge syringe at 4 and 10 days of age, and by snipping the tail in a fed state (18.00 hours) biweekly after 3 weeks until 12 weeks of age. Plasma glucose was measured by a Beckman Glucose Analyzer 2 (Beckman Instruments, Fullerton, Calif, USA). Blood pressure was measured in unanaesthetized state ( 15.00 to 18.00 hours) by an indirect tail-cuff method biweekly after 5 weeks of age. At 12 weeks of age, each animal was put into a metabolic cage for $24 \mathrm{~h}$ and metabolic studies were performed; i. e. food and water intake, urine volume and urinary glucose 


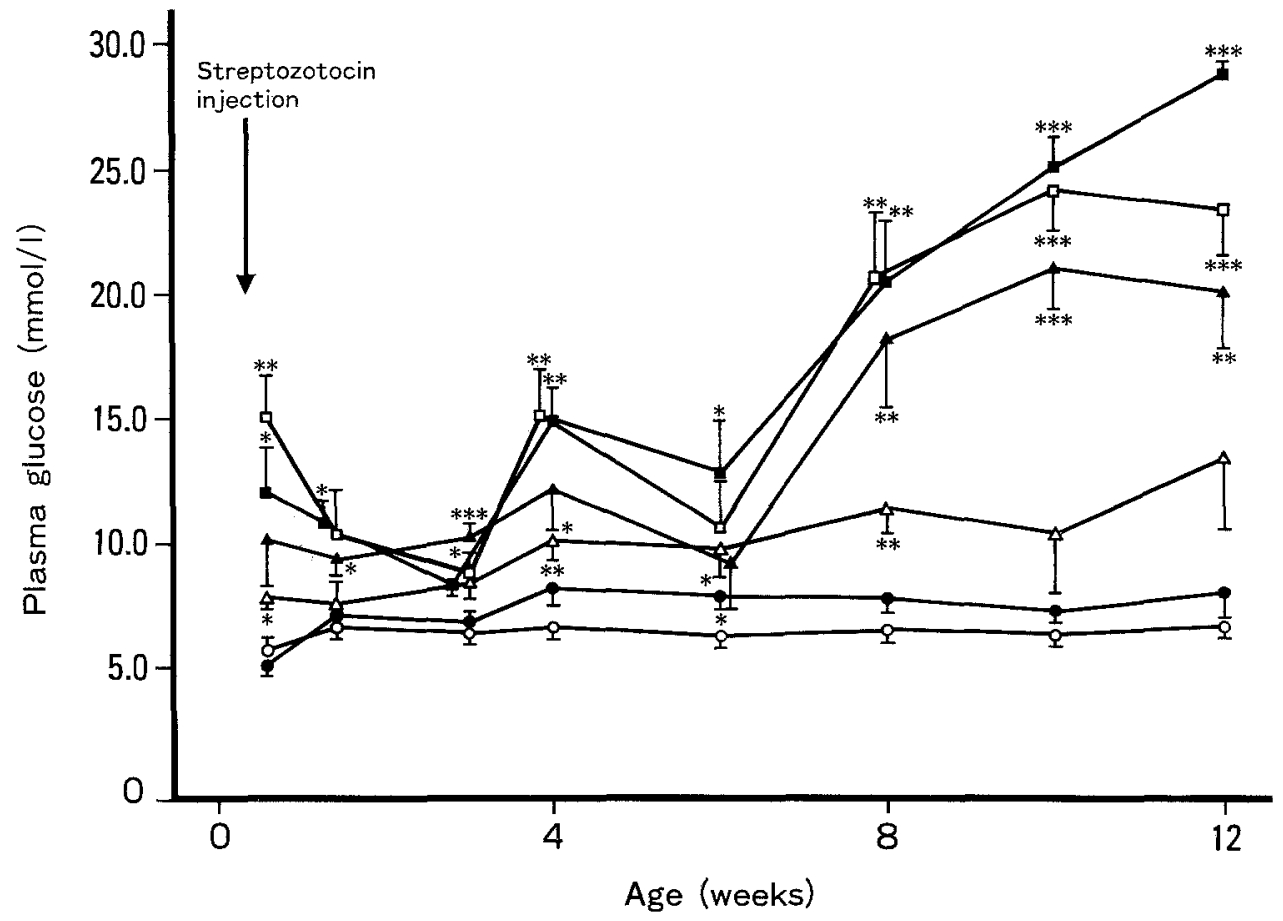

Fig. 1. Changes in plasma glucose levels in male spontaneously hypertensive rats treated with various doses of streptozotocin (STZ) at 2 days of age. $O=$ control (vehicle) $=25.0 \mathrm{mg} / \mathrm{kg}$ of STZ, $\Delta=37.5 \mathrm{mg} / \mathrm{kg}, \Delta=50.0 \mathrm{mg} / \mathrm{kg}$, $\square=62.5 \mathrm{mg} / \mathrm{kg}, \boldsymbol{\square}=75.0 \mathrm{mg} / \mathrm{kg}$. $* ; p<0.05, * * ; p<0.01, * * * ; p<$ 0.001 vs. control. Results are expressed as mean $\pm \mathrm{SEM}$

Table 1. Some characteristics of 12-week-old male spontaneously hypertensive rats (SHR) treated with various dosages of streptozotocin at 2 days of age

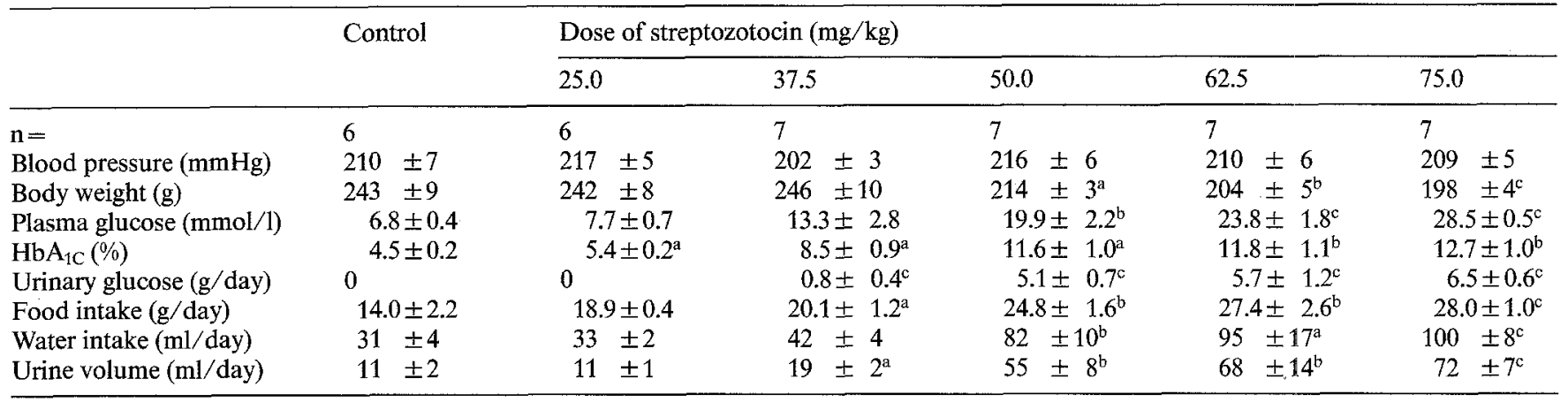

Results are mean \pm SEM. ${ }^{a} p<0.05 ;{ }^{b} p<0.01 ;{ }^{c} p<0.001$ vs. control. HbA 1 , glycosylated haemoglobin. Blood pressure was measured at 11 weeks of age. Control rats received vehicle

were determined. At this time, blood samples were also used for determination of glycosylated haemoglobin $\left(\mathrm{HbA}_{1 \mathrm{C}}\right)$ by aminophenylboronic acid affinity chromatography (Isolab Inc., Akron, Ohio, USA).

\section{Statistical analysis}

For statistical analysis, a two-tailed unpaired Student's t-test was used. The results were considered to be significant when $p$ was less than 0.05 . The values are given as mean \pm SEM.

\section{Results}

Figure 1 shows serial changes of plasma glucose in STZ-treated and control rats throughout the experimental course. At age 4 days, 2 days after STZ treat- ment, plasma glucose was elevated in all STZ-treated groups except the lowest dose group $(25.0 \mathrm{mg} / \mathrm{kg}) \mathrm{com}$ pared to controls, and the glycaemic level was almost dependent on the STZ dose administered. At 10 days and 3 weeks of age, however, the elevated plasma glucose levels transiently fell but remained above controls in the groups of 62.5 and $75.0 \mathrm{mg} / \mathrm{kg}$ of STZ. No changes were seen in the groups at smaller doses. At $50.0 \mathrm{mg} / \mathrm{kg}$ and more of STZ, a small peak of plasma glucose was noticed at 4 weeks of age, followed by another slight fall in plasma glucose at age 6 weeks. Overt hyperglycaemia gradually developed after 8 weeks of age and continued up to 12 weeks in these animals. In the $37.5 \mathrm{mg} / \mathrm{kg}$ group, plasma glucose level was moderately high, approximately two-fold of controls throughout the experimental course. At $25.0 \mathrm{mg} / \mathrm{kg}$ of STZ, 
however, plasma glucose was slightly but not significantly elevated compared with controls.

Blood pressure rose with age in all rats, both controls and STZ-treated, regardless of dose; i.e., STZ had no effect on the development of hypertension in SHR. Systolic blood pressures of the highest dose STZ $(75.0 \mathrm{mg} / \mathrm{kg})$ and control groups were $129 \pm 7$ and $136 \pm 2$ at 5 weeks, $159 \pm 4$ and $162 \pm 7$ at 7 weeks, $189 \pm 5$ and $181 \pm 8 \mathrm{mmHg}$ at 9 weeks respectively. Average values for blood pressure at 11 weeks did not differ between STZ-treated and control groups (Table 1).

Body weight before STZ injection (i. e. 2 days of age) was similar among all STZ-treated groups and controls. From 4 days to 8 weeks of age, body weight increased consistently and did not differ among STZ-treated and control groups $(167 \pm 5 \mathrm{~g}$ in $25.0 \mathrm{mg} / \mathrm{kg}, 187 \pm 9 \mathrm{~g}$ in $37.5 \mathrm{mg} / \mathrm{kg}, 167 \pm 3 \mathrm{~g}$ in $50.0 \mathrm{mg} / \mathrm{kg}, 169 \pm 7$ in $62.5 \mathrm{mg} /$ $\mathrm{kg}, 156 \pm 1 \mathrm{~g}$ in $75.0 \mathrm{mg} / \mathrm{kg}$ vs $170 \pm 7 \mathrm{~g}$ in controls at 8 weeks). After puberty, namely at age 8 weeks or older, however, the weight gain became smaller in groups treated with $50.0 \mathrm{mg} / \mathrm{kg}$ and more of STZ than that in those treated with lower dose or in control animals. At 12 weeks of age average body weight was significantly different $(p<0.05)$ between higher and lower dosetreated groups (Table 1 ), but a weight loss never occurred in any groups of STZ-treated animals.

Metabolic responses at 12 weeks of age are summarized in Table $1 . \mathrm{HbA}_{1 \mathrm{C}}$ increased significantly $(\mathrm{p}<$ 0.05 ) even at $25.0 \mathrm{mg} / \mathrm{kg}$ of STZ compared to controls, and its increase was dose-dependent. Among groups with higher STZ doses $(50.0,62.5$, and $75.0 \mathrm{mg} / \mathrm{kg})$, the difference in plasma glucose was also significant $(50.0$ vs. $75.0 \mathrm{mg} / \mathrm{kg}$ of STZ; $p<0.01,62.5$ vs. $75.0 \mathrm{mg} / \mathrm{kg}$ of STZ; $p<0.05$ ), but the difference in $\mathrm{HbA}_{1 C}$ did not reach statistical significance. Urinary glucose was detected in the group treated at $37.5 \mathrm{mg} / \mathrm{kg}$, and markedly increased in groups treated with $50.0 \mathrm{mg} / \mathrm{kg}$ and more. Food intake, water intake and urine volume increased according to STZ dose.

The mortality rate during the 12 -week observation was $12 \%$ for STZ-treated rats and $14 \%$ for control rats, most of which died before weaning.

\section{Discussion}

A few rat models studying a combination of diabetes mellitus and hypertension have been reported. Koletsky [2] has developed a genetically obese variant of SHR which has mild hyperglycaemia, marked hyperinsulinemia associated with hyperplastic pancreatic islets, and hyperlipidemia. This model, however, may be likened to Cushing's disease rather than diabetes mellitus because of hyperadrenocorticism [7]. On the other hand, some investigators $[3,4]$ have produced hypertension by clipping the renal artery in STZ-induced diabetic rats.
However, this type of hypertension is rare in humans compared to essential hypertension.

Chemically induced diabetes has been reported in SHR in which hypertension in resembles essential hypertension in humans. Hashimoto [8], who induced alloxan diabetes in 10-week-old SHR and maintained them for 18 months, has found lowering of systolic blood pressure after alloxan injection followed by a gradual rise to the control level, probably due to renal complications. Although plasma glucose was not measured quantitatively, these animals lost body weight markedly. Similarly, Iams et al. [9] induced alloxan diabetes in 5-month-old SHR. In their study, blood pressure fell markedly, and $52 \%$ of male and $80 \%$ of female rats died during the 8 weeks of observation because of severe diabetes. On the other hand, Somani et al. [10] gave various doses of STZ to 20- to 22-week-old male SHR. In those treated with $25.0 \mathrm{mg} / \mathrm{kg} \mathrm{STZ}$, moderate hyperglycaemia (plasma glucose; $12 \mathrm{mmol} / 1$ ) developed without reduction of body weight, but blood pressure was significantly lowered compared to controls. When larger doses of STZ were given, weight loss, overt hyperglycaemia and the reduction of blood pressure occurred in all rats, with these changes being STZ dosedependent. Diabetes induced by either STZ or alloxan has a depressor effect in adult SHR. Thus, animal models of diabetes with persistent hypertension have been unavailable.

By contrast, the present results demonstrate that neonatal STZ treatment does not disturb the development of hypertension in SHR. The reason why the timing of STZ administration makes the difference in its effects on blood pressure is unclear from our results. It may be related to differences in the development pattern of diabetes, i. e. diabetes appears very gradually in the neonatal model and abruptly in the adult one. This interesting observation needs further study to clarify the mechanism.

In the present study the relationship between STZ dose and the metabolic responses was clearly demonstrated. When $50.0 \mathrm{mg} / \mathrm{kg}$ or more STZ was given, moderately severe diabetes developed at the age of 12 weeks. Even in those rats treated with the lowest dose of STZ $(25.0 \mathrm{mg} / \mathrm{kg}), \mathrm{HbA}_{1 \mathrm{C}}$ was slightly but significantly higher than that of controls.

In this study less than $15 \%$ of the animals died during the observation period, mostly within 4 weeks of age. The mortality was not directly related to STZ treatment, because its rate was substantially the same as that in control.

In conclusion, we successfully produced an animal model of mild to severe Type 2 diabetes associated with genetic hypertension by administration of various doses of STZ in neonatal spontaneously hypertensive rats. This model may be useful particularly in studying the combined effects of hypertension and diabetes on large and small vessels of various organs. 


\section{References}

1. Drury PL (1983) Diabetes and arterial hypertension. Diabetologia 24: $1-9$

2. Koletsky S (1973) Obese spontaneously hypertensive rats - a model for study of atherosclerosis. Exp mol Path 19:53-60

3. Mauer SM, Steffes MW, Azar S, Sanderg SK, Brown DM (1978) The effects of Goldblatt hypertension on development of the glomerular lesions of diabetes mellitus in the rat. Diabetes 27: 738-744

4. Factor SM, Bhan R, Minase T, Wolinsky H, Sonnenblick EH (1981) Hypertensive-diabetic cardiomyopathy in the rat. An experimental model of human disease. Am J Pathol 102:219-228

5. Portha B, Picon L, Rosselin G (1979) Chemical diabetes in the adult rat as the spontaneous evolution of neonatal diabetes. Diabetologia 17: 371-377

6. Bonner-Weir S, Trent DF, Honey RN, Weir GC (1981) Responses of neonatal rat islets to streptozotocin. Limited B-cell regeneration and hyperglycemia. Diabetes 30: 64-69
7. Wexler BC, Iams SG, McMurtry JP(1980) Pathophysiological differences between obese and non-obese spontaneously hypertensive rats. Br J Exp Path 61: 195-207

8. Hashimoto Y (1969) Effect of alloxan diabetes induced in spontaneously hypertensive rats. Jap Circul J 33: 1315-1338

9. Iams SG, Wexler BC (1977) Alloxan diabetes in spontaneously hypertensive rats: gravimetric, metabolic and histopathological alterations. Br J Exp Path 58: 177-199

10. Somani P, Singh HP, Saini RK, Rabinovitch A (1979) Streptozotocin-induced diabetes in the spontaneously hypertensive rat. Metabolism 28: 1075-1077

Received: 26 May 1986

and in revised form: 3 September 1986

Dr. Masanori Iwase

Second Department of Internal Medicine

Faculty of Medicine, Kyushu University

Maidashi 3-1-1, Higashi-ku,

Fukuoka City, 812 Japan 